\title{
PENJADWALAN PRODUKSI DENGAN METODE JOHNSON DAN HEURISTIC UNTUK MEMINIMASI MAKESPAN, TOTAL FLOW TIME, SERTA IDLE TIME
}

\author{
Dyah Retno $\mathbf{P}^{1}$, Hima Khusnita ${ }^{2}$
}

\begin{abstract}
ABSTRCT
Product scheduling system that used by PT. Berjaya Sekawanindo for this time, only concidering one purpose criteria for product scheduling is how to finishing all of demand fastest. With only concidering one urpose criteria, cause there are another criterias which neglectfully.

In this task, we try to aplicating some scheduling system which considering some criterias, then will used in scheduling process at PT. Berjaya Sekawanindo for get most optimal product scheduling which considering criterias : makespan minimation, flow time total minimation and idle time total.

From scheduling performancy result can be seen that heuristik scheduling method which multy purpose is more optimal than methode which use one makespan. Production scheduling result from two of methode have equal makespan value and idle time total, but have deferent flow time total.flow time total with heuristik method have a small value than one makespan criteria. The result from product scheduling which using heuristik method multy purpose at PT. Berjaya Sekawanindo is 1-4-3-2-5-6-7 with makespan value 22,33 ; total flow time $=107,49$; and total idle time $=47,84$. From in a serries with considering makespan, flow time and idle time be found that schedule serries which job time minimalitation there are system consederation with scheduling which use by factory for this time which only considering one makespan.
\end{abstract}

Key Words : Product Scheduling, Total Job Time Minimation

\section{PENDAHULUAN}

Perkembangan industri khususnya industri manufacturing dewasa ini, telah memaksa kita untuk selalu mencari alternatif terbaik dalam usaha memenuhi kebutuhan yang beraneka ragam. Tetapi karena terbatasnya sumber daya perusahaan maka usaha tersebut menjadi sulit untuk dilakukan. Karena itu peningkatan utilitas dan produktivitas masing masing sumber daya harus segera dilakukan. Khususnya sumber daya yang terlibat langsung di bidang produksi.

Sistem penjadwalan produksi yang dipakai selama ini oleh PT. Berjaya
Sekawanindo hanya mempertimbangkan satu kriteria tujuan dalam melakukan suatu penjadwalan produksi yaitu bagaimana terselesaikannya semua permintaan yang ada dengan cepat. Maka tidak menutup kemungkinan akan ada kriteria kriteria lain yang diabaikan yang kadang sangat berpengaruh terhadap utulitas dan produkstivitas sumber daya yang ada pada perusahaan khususnya mesin dan tenaga kerja langsungnya.

Untuk itu dalam hal ini metode penjadwalan dengan menggunakan metode heuristik multi tujuan yang mempertimbangkan berbagai kriteria diaplikasikan dalam proses pembuatan 
jadwal produksi guna mendapatkan suatu penjadwalan produksi yang optimal dengan mempertimbangkan kriteria kriteria antara lain : minimasi makespan, minimasi total flow time serta minimasi total idle time.

\section{TINJAUAN PUSTAKA}

\section{Pengukuran Waktu Standart dan Penetapan Waktu Baku}

Pengukuran kerja adalah suatu metode penetapan keseimbangan antara jalur manusia yang dikontribusikan dengan jumlah output yang dihasilkan. Waktu baku merupakan waktu yang dibutuhkan seorang pekerja yang memiliki tingkat kemampuan rata rata untuk menyelesaikan suatu pekerjaan. Disini sudah meliputi waktu kelonggaran yang diberikan dengan memperhatikan situasi dan kondisi pekerjaan yang harus diselesaikan tersebut. Dengan demikian waktu yang dihasilkan dalam aktivitas pengukuran kerja ini dapat digunakan untuk menyusun jadwal kerja. Hasil ini menyatakan berapa lama suatu kegitan harus berlangsung dan berapa output yang seharusnya dapat diselesaikan. Selain itu juga bisa menentukan berapa jumlah tenaga kerja yang dibutuhkan untuk menyelesaikan suatu pekerjaan.

Teknik pengukuran waktu kerja pada garis besarnya dapat dibagi dua bagian yaitu secara langsung dan secara tidak langsung. Cara pertama dilakukan ditempat dimana pekerjaan yang diukur dijalankan. Cara ini adalah menggunakan jam henti dan sampling kerja. Cara yang lain adalah dilakukan oleh pengamat tanpa harus berada ditempat pekerjaan yang diukur. Cara ini bisa dilakukan dalam aktivitas data waktu baku ( standart data ) dan waktu gerakan ( predetermined time system )

\section{Penetapan Jumlah Siklus Kerja}

Standar error dari harga rata rata untuk setiap elemen kerja dapat dinyatakan dalam rumus :

$$
\delta_{x}=\frac{\delta^{\prime}}{\sqrt{N}}
$$

dimana :

$$
\delta_{-}=\text {Penyimpangan standar dari }
$$

distribusi rata rata

$$
\delta^{\prime}=\text { Penyimpangan standar dari }
$$

populasi untuk elemen kerja yang ada

$$
N=\text { Jumlah pengamatan untuk }
$$

elemen kerja yang diukur

Penyimpangan standart dinyatakan dengan tanda $\delta$ ( sigma ), yang dinyatakan dalam formula berikut :

$$
\begin{aligned}
& \delta=\sqrt{\frac{\left(x_{1}-\bar{x}\right)^{2}+\left(x_{2}-\bar{x}\right)^{2}+\cdots+\left(x_{n}-\bar{x}\right)^{2}}{N}} \\
& \delta=\sqrt{\frac{\sum(x-\bar{x})^{2}}{N}}=\sqrt{\frac{\sum x^{2}}{N}-(\bar{x})^{2}} \\
& \delta=\sqrt{\frac{\sum x^{2}}{N}-\left[\frac{\sum x}{N}\right]^{2}}=\frac{1}{N} \sqrt{N \sum x^{2}-\left(\sum x\right)^{2}}
\end{aligned}
$$

dengan mengkombinasikan formula yang ada maka diperoleh :

$$
\delta_{\bar{x}}=\frac{\frac{1}{N} \sqrt{N \sum x^{2}-\left(\sum x\right)^{2}}}{\sqrt{N}}
$$


Untuk menetapkan berapa jumlah observasi yang seharusnya dibuat $\left(N^{\prime}\right)$ maka disini harus diputuskan terlebih dahulu tingkat kepercayaan ( confidence level) dan derajat ketelitian ( degree of accuracy) untuk pengukuran ini. Di dalam pengukuran aktivitas kerja biasanya akan diambil $95 \%$ confidence level dan $5 \%$ degree of accuracy. Dengan demikian formula diatas dapat ditulis lagi sebagai berikut :

$$
\begin{aligned}
& 0,05 \bar{x}=2 \delta \bar{x} \text { atau } 0,05 \frac{\sum x}{N}=2 \delta \bar{x} \\
& 0,05 \frac{\sum x}{N}=2 \frac{\frac{1}{N} \sqrt{N\left(\sum x^{2}-\left(\sum x\right)^{2}\right)}}{\sqrt{N^{\prime}}} \\
& N^{\prime}=\left(\frac{20 \sqrt{N \sum x^{2}-\left(\sum x\right)^{2}}}{\sum x}\right)^{2}
\end{aligned}
$$

dimana jumlah pengamatan atau pengukuran yang seharusnya dilaksanakan. Apabila selanjutnya dikehendaki tingkat kepercayaan $95 \%$ dan tingkat ketelitian $10 \%$ maka rumus akan berubah

$N^{\prime}=\left[\frac{20 \sqrt{N \sum x^{2}-\left(\sum x\right)^{2}}}{\sum x}\right]^{2}$

\section{Uji Keseragaman Data}

Test keseragaman data perlu kita lakukan terlebih dahulu sebelum kita menggunakan data yang kita peroleh untuk menetapkan waktu standart. Test keseragaman data bisa dilaksanakan dengan cara visual atau dengan mengaplikasikan peta control.

Test keseragaman data secara visual dilakukan secara sederhana, mudah dan cepat dengan cara melihat data yang terkumpul dan

seterusnya mengidentifikasikan data yang terlalu ekstrem.

Peta kontrol adalah suatu alat yang tepat guna dalam mengetes keseragaman data atau keajegan data. Batas kontrol atas ( BKA ) dan batas kontrol bawah ( BKB ) dapat dicari dengan formulasi berikut

$$
\begin{aligned}
& B K A=\bar{x}+3 S D \\
& B K B=\bar{x}-3 S D \\
& \text { dimana : } \bar{x}=\bar{x} \text { dari group }
\end{aligned}
$$

\section{Penetapan Waktu Normal}

\begin{tabular}{|c|c|c|c|}
\hline \multicolumn{2}{|c|}{ SKILL } & \multicolumn{2}{|c|}{ EFFORT } \\
\hline$+0,15 \mathrm{Al}$ & Superskill & $+0,13 \mathrm{Al}$ & Superskill \\
\hline$+0,13 \mathrm{~A} 2$ & & $+0,12 \mathrm{~A} 2$ & \\
\hline$+0,11 \mathrm{~B} 1$ & Excellent & $+0,10 \mathrm{Bl}$ & Excellent \\
\hline$+0,08 \mathrm{~B} 2$ & & $+0,08 \mathrm{~B} 2$ & \\
\hline$+0,06 \mathrm{Cl}$ & Good & $+0,05 \mathrm{C} 1$ & Good \\
\hline$+0,03 \mathrm{C} 2$ & & $+0,02 \mathrm{C} 2$ & \\
\hline $0,00 \mathrm{D}$ & Average & $0,00 \mathrm{D}$ & Average \\
\hline$-0,05 \mathrm{E} 1$ & Fair & $-0,04 \mathrm{E} 1$ & Fair \\
\hline$-0,10 \mathrm{E} 2$ & & $-0,08 \mathrm{E} 2$ & \\
\hline$-0,16 \mathrm{Fl}$ & Poor & $-0,12 \mathrm{Fl}$ & Poor \\
\hline$-0,22 \mathrm{~F} 2$ & & $-0,17 \mathrm{~F} 2$ & \\
\hline \multicolumn{2}{|c|}{ CONDITION } & \multicolumn{2}{|c|}{ CONSISTENCY } \\
\hline$+0,06 \mathrm{~A}$ & Ideal & $+0,04 \mathrm{~A}$ & Ideal \\
\hline$+0,04 \mathrm{~B}$ & Excellent & $+0,03 \mathrm{~B}$ & Excellent \\
\hline$+0,02 \mathrm{C}$ & Good & $+0,01 \mathrm{C}$ & Good \\
\hline $0,00 \mathrm{D}$ & Average & $0,00 \mathrm{D}$ & Average \\
\hline$-0,03 E$ & Fair & $-0,02 \mathrm{E}$ & Fair \\
\hline$-0,07 \mathrm{~F}$ & Poor & $-0,04 \mathrm{~F}$ & Poor \\
\hline
\end{tabular}

Waktu normal $=$ waktu observasi rata rata $\mathrm{x}$ Performance rating

Tabel 1

Performance Rating dengan Westing House

\section{Penetapan Waktu Baku}

Waktu normal untuk suatu elemen operasi kerja adalah semata mata menunjukkan bahwa seorang operator yang berkualifikasi baik akan bekerja 
menyelesaikan pekerjaan pada kecepatan normal. Waktu longgar diklasifikasikan menjadi tiga yaitu :

- Kelonggaran waktu untuk kebutuhan personal

- Kelonggaran waktu untuk melepas lelah

- Kelonggaran waktu karena keterlambatan keterlambatan

Sehingga waktu baku ( waktu standar ) dapat ditetapkan sebagai berikut :
Waktu baku $=$ waktu normal +( waktu normal $\mathrm{x}$ allowance )

atau

Waktu baku $=$ waktu normal $\mathrm{x}$

$$
\frac{100 \%}{100 \%-\text { allowance }}
$$

Dimana : Waktu normal = waktu observasi rata rata $\mathrm{x}$ performance rating

\section{Penjadwalan Produksi}

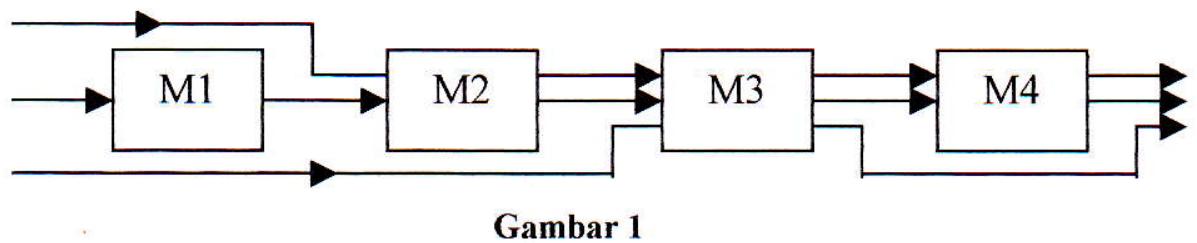

Pola Aliran Flow shop

\section{Algoritma Johnson}

Yaitu dengan menciptakan $(\mathrm{m}-1)$ jadwal yang mungkin dan memilih yang terbaik

- Untuk jadwal pertama

$$
\begin{aligned}
& t_{i, 1}=t_{i, 1} \\
& t_{i, 2}^{*}=t_{i, 2}
\end{aligned}
$$

ini adalah processing time pada mesin pertama dan mesin terakhir

- Untuk jadwal kedua

$$
\begin{aligned}
t_{i, 1}^{*} & =t_{i, 1}+t_{i, 2} \\
t^{*}{ }_{i, 2} & =t_{i, 2}+t_{i, m-1}
\end{aligned}
$$

ini adalah processing time pada 2 mesin pertama dan 2 mesin terakhir

- Untuk jadwal ke- k

$$
\begin{aligned}
t_{i, 1}^{*} & =\sum_{k=1}^{k} t_{i, k} \\
t^{*} i, 2 & =\sum_{k=1}^{k} t_{i, m-k+1}
\end{aligned}
$$

Pendekatan ini belum menjamin akan terbentuknya jadwal dengan makespan minimum. Sangat tergantung pada processing time dari job job yang akan dijadwalkan.

\section{Metode Campbell, Dudek, Smith}

Metode ini digunakan sebagai pendekatan untuk mendapatkan jadwal dengan makespan minimum. Dari hasilnya akan digunakan sebagai jadwal awal pada penerapan metode heuristik dengan multi tujuan. 
Step 1 : Pada saat $\mathrm{k}=1$, hitung $t^{*}{ }_{i, 1}$ dan $t^{*}{ }_{i, 2}$

Step 2 : Jadualkan job job sebanyak $m$ dengan menggunakan aturan Johson.

Dimana $t_{i, 1}$ dan $t_{i, 2}$ adalah $t^{*}{ }_{i, 1}$ dan $t_{i, 2}^{*}$ dari step 1. Simpan jadwal ini dan hitung makespannya jika makespan yang dihitung adalah yang terkecil, maka simpan urutan dan nilai makespannya.

Step 3 : Jika $k=(m-1)$, stop. jadwal paling akhir adalah jadwal yang diterapkan.

Jika $\mathrm{k} \neq(\mathrm{m}-1)$, tambahkan $\mathrm{k}$ dengan 1 dan kembali ke step 1 .

Makespan dapat dihitung, dimana nilainya sama dengan waktu dimana job telah selesai diproses pada mesin terakhir. Completion time dari job terakhir sama dengan jumlah processing time semua job pada mesin terakhir ditambah dengan jumlah waktu idle pada semua periode

\section{Algoritma Heuristik untuk Minimum}

\section{Flow Time, Makespan dan idle time}

Step 1: Selesaikan dengan metode Campbell, Dudek, Smith yang meminimumkan makespan dan dapatkan satu jadwal.

Dapatkan satu jadwal dengan mengubah urutan job yaitu gantikan job yang berada pada urutan ke- $r$ dengan urutan $r+1$. Pilih jadwal yang menghasilkan makespan minimum. Lanjutkan proses tersebut dengan job yang berpasangan,

dimana

$V r, i \leq r \leq n-1$ dan pilih jadwal yang menghasilkan makespan yang lebih kecil

Jadual ini menjadi daftar jadwal ' $S$ ' dengan makespan dan total flow time ' $F$ '.

Step 2: Hitung nilai nilai berikut untuk job yang berada pada posisi ke- $r$ dalam jadual $\mathrm{S}$, dimana $1 \leq r \leq n-1$

$D_{[r]}=\sum_{j=1}^{m} t_{[r], j}-\sum_{j=1}^{m} t_{[r+1], j}$

$D_{r]}=\sum_{j=1}^{m}\left\{(m-j+1) t_{[r], j}\right\}-\sum_{j=1}^{m}\left\{(m-j+1) t_{[r+1, j}\right\}$

Step 3 : Buat daftar job yang nilai $D_{[r]} \geq 0$

Step 4 : Jika jadwal ( list ) kosong, lanjutkan ke step 10 , selain itu lanjutkan ke step 5

Step 5 : List job disusun dengan urutan menurun menurut nilai $D_{[r]}$ yang tertinggi disusun terlebih dahulu. jika terjadi kesamaan nilai $D_{[r]}$, maka ranking disusun dengan mempertimbangkan nilai $D_{[r]}^{\prime}$ yang tinggi.

Step 6: Sebut job yang berada pada urutan pertama sebagai job Q saling tukarkan posisi job yang berada pada urutan $Q$ dan job yang berada pada posisi

$\mathrm{Q}+1$ dalam jadual S. sebut jadwal yang dihasilkan sebagai $S^{\prime}$. Hitung makespan ( $\left.\mathbf{M}^{\prime}\right)$, total flow time (F') dan total idle time 
(I'). Dari sini dapat dilihat bahwa semakin besar kesempatan mengurangi flow time ketike job yang bersangkutan digantikan oleh job yang sesuai.

Step 7 : Hitung penambahan relatif makespan, flow time dan idle time dari $S^{\prime}$ dengan $\mathrm{S}$.

$R S^{\prime}=\frac{M^{\prime}-\min \left(M^{\prime}, M\right)}{\min \left(M^{\prime}, M\right)}+\frac{F^{\prime}-\min \left(F^{\prime}, F\right)}{\min \left(F^{\prime}, F\right)}+\frac{I^{\prime}-\min \left(I^{\prime}-I\right)}{\min \left(I^{\prime}, I\right)}$

dan

$R S=\frac{M-\min \left(M^{\prime}, M\right)}{\min \left(M^{\prime}, M\right)}+\frac{F-\min (F, F)}{\min (F, F)}+\frac{I-\min \left(I^{\prime}, I\right)}{\min \left(I^{\prime}, I\right)}$

Step 8: Jika $R S^{\prime}<R S$, kemudian generate $S^{\prime}$, menjadi daftar baru sebagai S.(dimana semua parameter $\mathrm{S}^{\prime} \mathrm{S}^{\prime}$; $\mathrm{M}=\mathrm{M}^{\prime}$; $\mathrm{F}=\mathrm{F}^{\prime}$; I=I' ) dan kembali ke step 2. Selain itu ke step 10.

Step 9 : Hilangkan job Q dari kumpulan job yang belum terjadwalkan. Jika urutan yang terbentuk belum urutan yang terakhir, kembali step 6. Jika urutan yang terbentuk merupakan urutan terakhir lanjutkan step 10.

Step 10 : Daftar tersebut dengan makespan, total flow time dan idle time mesin mesinnya menjadi solusi. stop

\section{METODOLOGI PENELITIAN}

\section{Jenis Data yang Diperlukan}

Data yang diperlukan meliputi data profil dan sistem produksi perusahaan, data jenis produk, struktur produk, permintaan produk, jenis mesin, routing pengerjaan masing-masing job, waktu proses tiap operasi, proses produksi serta due date dari job-job tersebut.

\section{Tahapan Pengolahan Data}

Proses pengolahan data meliputi beberapa tahapan antara lain :

1. Perhitungan Waktu Standart

2. Menentukan matrik waktu standart (dalam satuan jam) pengerjaan suatu job pada masing-masing mesin.

3. Pembuatan jadwal dengan menerapkan metode johnson dan heuristic dengan minimasi makespan, flow time, dan iddle time.

4. Pembuatan Gantt Chart

\section{HASIL DAN PEMBAHASAN}

Waktu standart atau waktu baku operasi diperoleh dari waktu rata rata pengamatan yang kemudian diberi rating dan allowance atau kelonggaran. Pemberian faktor rating dan allowance seperti tercantum dalam lampiran tentang data hasil pengamatan waktu kerja masing masing operasi.

Kelonggaran waktu atau allowance yang diberikan berdasarkan pertimbangan pertimbangan :

- Hasil interview dengan kepala bagian produksi menyatakan kelonggaran yang diberikan oleh perusahaan $5 \%$.

- Kondisi pekerjaan yang relatif ringan , Tidak memerlukan konsentrasi pikiran 
yang tinggi. Kondisi lingkungan fisik yang baik dan adanya jam istirahat resmi jam $12.00-12.30$.

- Waktu kerja efektif selama 7,5 jam.

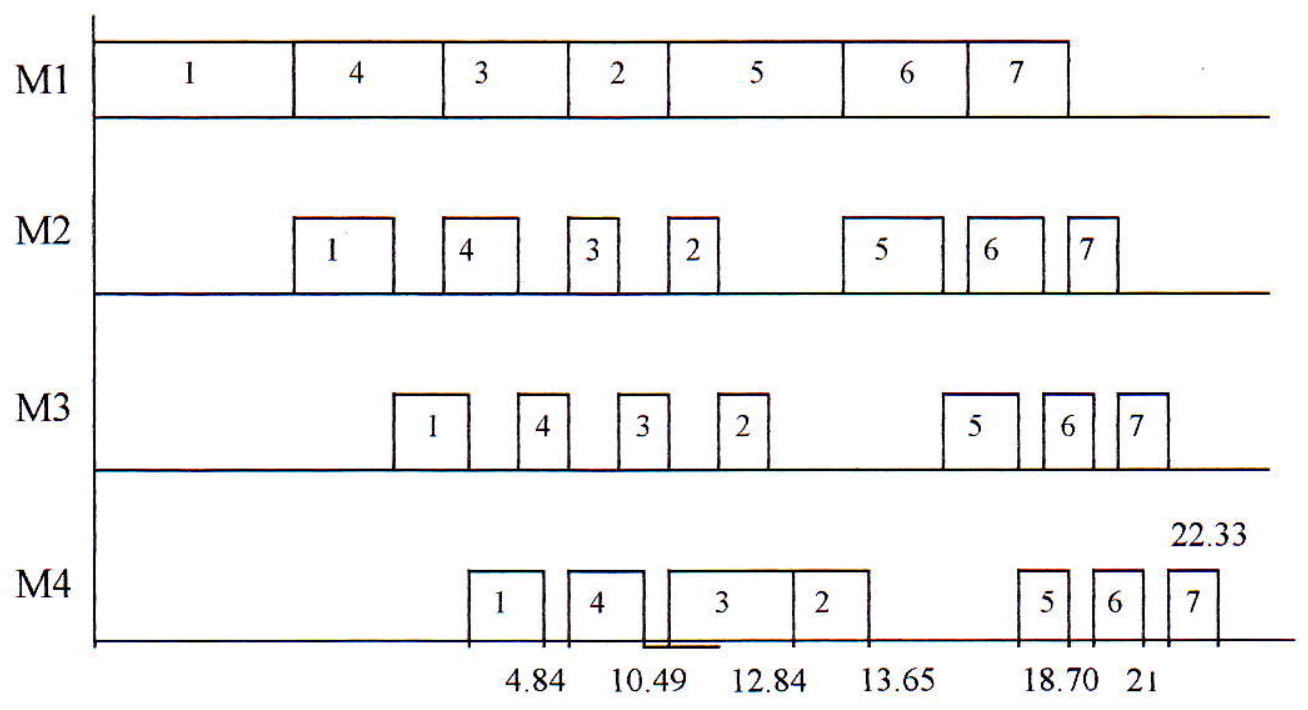

Gambar 2

Gantt Chart hasil penjadwalan dengan metode heuristik



Gambar 3

Gantt Chart hasil metode Campbell Dudek Smith 
Berdasarkan gambar diatas diperoleh perbandingan pencapaian performansi sebagai berikut :

Tabel 2

Perbandingan pencapaian performansi

\begin{tabular}{|l|c|c|}
\hline Kriteria & $\begin{array}{l}\text { Heuristik } \\
\text { Multi Tujuan }\end{array}$ & $\begin{array}{l}\text { CDS Kriteria } \\
\text { Makespan }\end{array}$ \\
\hline Makespan & 22,33 & 22,33 \\
\hline Total Flow Time & 107,49 & 110,81 \\
\hline Total Idle Time & 47,84 & 47,84 \\
\hline
\end{tabular}

Dari hasil performansi penjadwalan yang dicapai dapat dilihat bahwa metode penjadwalan heuristik multi tujuan lebih optimal dibanding metode yang menggunakan satu kriteria tujuan ( makespan). Jadwal produksi yang didapat dari kedua metode diatas mempunyai nilai makespan dan total idle time yang sama, tetapi mempunyai total flow time yang berbeda. Dimana total flow time dengan metode heuristik mempunyai nilai yang lebih kecil dari metode satu kriteria tujuan.

\section{KESIMPULAN}

Setelah dilakukan analisa maka dapat ditarik kesimpulan sebagai berikut :

1. Dari hasil penjadwalan produksi dengan menggunakan metode heuristik multi tujuan pada PT. Berjaya Sekawanindo menghasilkan urutan jadwal 1-4-3-2-56-7 dengan nilai makespan $=22,33$; total flow time $=107,49$; dan total idle time $=47,84$.

2. Dari urutan jadwal yang diperoleh dengan mempertimbangkan makespan, flow time serta idle time didapat urutan jadwal yang meminimalkan total waktu job berada dalam sistem dibanding dengan menggunakan penjadwalan yang dipakai selama ini oleh perusahaan yang hanya mempertimbangkan satu kriteria tujuan.

\section{DAFTAR PUSTAKA}

Baker, Kenneth R., Sequensing Rules and Due Date Assigment in A Job Shop, Manajement Sceince, Vol. 30 n0. 9.

Dervitsiotis, Kostas N., Operation

Management, Mc., Graw Hill, Inc., 1994.

Elsayed, Elsayed A. and Thomas Bbaucher,

Analysis and Control of Production

System, Prentice Hall Inc., New Jersey, 1985.

Morton, Thomas E. and David W. Pentico,

Heuristic Scheduling System, John

Wiley and Sons, New York, 1993.

Walpole, Ronsld and Raymond H. Myers,

Ilmu Peluang dan Statistik untuk

Insinyur dan Ilmuwan, ITB

Bandung, 1986.

Wignjosoebroto, Sritomo, Study Gerak dan

Waktu, Guna Widya, 1992. 